\title{
Designing low-cost "heart healthy bread": optimization using linear programing and 15-country comparison
}

\author{
Nick Wilson*, Nhung Nghiem, Sian Ryan, Christine Cleghorn, Nisha Nair and Tony Blakely
}

\begin{abstract}
Background: Bread is an important component of the diet in many countries and provides needed nutrients but also typically too much of other nutrients e.g., sodium. We therefore aimed to use linear programing to determine the optimal design of low-cost "heart healthy bread" (HHB) and to compare the results with commercial breads in 15 countries.
\end{abstract}

Methods: Optimization using linear programing focused on achieving set loaf prices (at NZ\$1.5 and \$3) and for a range of minimal sodium levels. Then within those constraints, levels of alpha-linolenic acid (ALA) were maximized, then dietary fiber, and then polyunsaturated fatty acids. Data from New Zealand (NZ) was used for the HHB designs and comparison nutrient and price data came from breads in 15 high-income countries.

Results: The optimized loaf costing NZ\$1.50 in ingredients (HHB\$1.5) was superior to the commercial white loafs in three out of the eight heart health nutrient categories. The optimized loaf that was high in linseed and cost NZ\$3 in ingredients (HHB\$3), was nutritionally superior to the commercial loafs with seeds/nuts in six out of the eight heart health categories (i.e., in terms of sodium, potassium, fatty acid ratio and fiber). In terms of value-per-weight, a commercial white loaf from the UK was slightly cheaper than the HHB\$1.50 loaf (at US\$0.07 vs US\$0.10 per $100 \mathrm{~g}$ loaf). But compared to the other seed/nut loafs, the HHB\$3 loaf was the best value at US\$0.17 per $100 \mathrm{~g}$, vs a mean of US\$0.85 per $100 \mathrm{~g}$ across international comparators.

Conclusions: This proof-of-concept study suggests it is possible to design breads that are nutritionally superior to commercially available breads from a heart health perspective, as well as being lower cost. Such HHB designs could be promoted by health agencies and utilized in conjunction with a government-funded bread voucher system for those at high risk of cardiovascular disease.

Keywords: Cardiovascular disease, Bread design, Linear programing, Optimization, Sodium, Fiber, Alpha-linolenic acid, Saturated fat

\section{Background}

The global burden of non-communicable diseases (NCDs) accounted for two of every three deaths (34.5 million) worldwide in 2010 [1]. Furthermore, a global estimate for 2013 indicated the high burdens of years lived with disability from: diabetes (29.5 million), cardiovascular disease (21.2 million) and cancer (6.7 million) [2].

Dietary risk factors are particularly important for NCDs such as cardiovascular disease (CVD) [3] and

\footnotetext{
* Correspondence: nick.wilson@otago.ac.nz

Department of Public Health, University of Otago, Wellington, PO Box 7343 Wellington, New Zealand
}

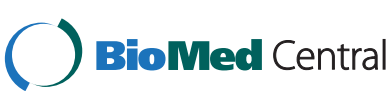

these include dietary intakes of sodium, fiber and types of fatty acids. One food which has all three of these nutrients is bread. It is also one of the most popular foods in many developed countries e.g., $8.7 \%$ of total energy in the United States, albeit the combined category of "bread, rolls and crackers" [4]. Even more so in Canada, "refined breads" contributed more dietary energy than all the other food groups in those aged 18 to 65 years (range by age/sex groups: 10.5 to $11.8 \%$ ), with wholegrain breads contributing another few percent (range: 2.4 to $4.1 \%$ ) [5]. For men in the United Kingdom, white bread was the second highest non-beverage food in 
those aged 19-64 years (by weight with a median of $46 \mathrm{~g}$ per day; interquartile range [IQR]: 18-93) after vegetables [6]. But for women it was less at a median of $27 \mathrm{~g}$ per day (IQR: 9-61).

Based on commercial varieties of bread available, there appears to be substantial flexibility around the levels of the main ingredients (e.g., flour, yeast, salt) and also additional ingredients such as nuts and seeds. For example, a number of European governments aim to reduce sodium intakes by regulating the maximal level of sodium in bread $[7,8]$. This action is supported by various modeling studies that suggest both health and economic advantages of reducing sodium in bread (e.g., for Argentina [9-11], Australia [12, 13], New Zealand [14] and South Africa [15]). Furthermore, there have been successful studies and interventions to replace sodium chloride in bread with potassium salts [16-18].

But other aspects of bread design can also be considered from a CVD prevention perspective given the evidence from systematic reviews around: increasing dietary fiber $[19,20]$ and increasing linseed (flaxseed) intake which is high in alpha-linolenic acid [21, 22]. Yet despite this evidence, our examination of the literature (as of June 2015) identified no optimization studies specifically relating to the design of heart healthy bread, and none concerning the design of low-cost healthier bread.

So to further progress thinking around this issue, we aimed to design optimized versions of low-cost "heart healthy breads" (HHBs). Our specific major aim was to determine, at a "proof-of-concept" level, if it was possible to design breads that had both improved nutrient levels from a CVD prevention perspective and which were relatively low-cost. Our secondary aims were: (i) to determine how these HHBs compared with commercial breads in 15 high-income countries; and (ii) to estimate the cost of mass production of HHB loafs using publicly-available data for the cost-structure data of bread manufacture.

We specifically aimed to use linear programing in our methods as this is an established tool in studying the optimization of food and diets where there are multiple nutritional and other objectives [23]. It has also been used previous around bread in diets e.g., for studying sodium and iodine in the diets of Indigenous Australians [24], for the inclusion of wholemeal bread in food aid in France [25], and for changing bread intake as part of improving nutrient intakes for the Italian population [26].

\section{Methods}

While more detailed steps follow, in summary this work began with literature searches for identifying potential bread ingredients and their nutritional value from a CVD prevention perspective. This was then followed by a determination of the specific nutrient constraints to be applied and optimization priorities set, for the analysis using linear programing. New Zealand nutrient and price data were used for the HHB designs and data for comparison with commercial breads were obtained for 15 high-income (OECD) countries from freely accessible nutrient databases that could be identified online. Publicly-available data for the cost-structure of bread manufacture from the Canadian baking industry was then used to better estimate the cost of mass production of HHB loafs.

\section{Potential ingredients considered for bread designs}

We considered the following potential bread ingredients from a CVD prevention perspective, based on how key bread components are described in the literature:

- A high potassium salt substitute, as this type of salt has been associated with blood pressure reduction in a meta-analysis [27]. There is also evidence that potassium chloride can achieve flavor compensation that allows for large reductions in sodium levels in bread [28].

- Wholemeal flour, given the evidence for reduced CVD risk as per three systematic reviews $[19,20$, 29] and an analysis of two large prospective studies [30]. Although outside of the CVD perspective, we note that dietary fiber from whole grains also appears to protect against colorectal cancer in another systematic review [31].

- Linseed, as this is high in dietary fiber, lignans and $\mathrm{n}-3$ polyunsaturated fatty acids (PUFA) and there is some evidence for CVD-related benefits as per three reviews [32-34] and a recent trial [35]. More specifically, two meta-analyses report blood pressure reduction associated with linseed consumption $[21,22]$.

- Walnut (English walnut), as there is evidence that this food can benefit cardiovascular health as per a systematic review [36] and another recent review [37]. Indeed, nut consumption more broadly is associated with reduced risk of both CVD and cancer according to a systematic review [38] and a large cohort study [39]. Given this we also considered the addition of other seeds that are known to be commonly used in commercial breads, i.e., sesame seeds, sunflower seeds and pumpkin seeds.

\section{Potential ingredients not included}

Plausible healthy bread ingredients from a CVD perspective identified in the literature included: soy protein [40], sourdough [41], and high phenolic olive oil [42]. But in this initial work we did not include these 
ingredients on the grounds of potentially relatively lower consumer acceptability.

\section{Constraints and optimization approach used for the linear programing}

Based on the above, the specific details on the constraints applied and optimization priorities are outlined in Table 1. To summarize, optimization focused on achieving two set loaf prices (at NZ\$1.5 and \$3) and for a range of minimal sodium levels. Then within those constraints, the first priority in the "objective function" was to maximize levels of alpha-linolenic acid (ALA) (an omega-3 fatty acid), followed by maximizing dietary fiber, and then maximizing polyunsaturated fatty acids (PUFA).

The simplex algorithm was used to solve these linear programing problems (see Briend et al. [23] for a detailed description of the linear programing). The problem of multiple objectives with priority levels is addressed with lexicographic goal programing, which involves a sequence of linear programing steps [43]. Most of the scenarios were modeled in Microsoft Excel 2010 (Excel Solver, Simplex method), but where there was a high level of complexity with the food combination options the $\mathrm{R}$ programing language was used (version 2.15.0, lpSolve package).

\section{Nutrient and price data for the HHBs}

The nutrient data for the HHBs was sourced from a New Zealand food composition database [44]. But, in some cases we had to use other sources such as a study on levels of alpha-linolenic acid covering nuts and seeds [45] and from the nutrient panel on the packaging (i.e., for the salt substitute). For the price data for HHB ingredients, the cheapest retail source for the ingredients were used, with these typically being supermarkets and online stores in New Zealand.

Table 1 Constraints and optimization targets for the design of the "heart healthy breads"

\begin{tabular}{|c|c|c|}
\hline Ingredients and nutrients & Constraints and optimization targets & Further details \\
\hline \multicolumn{3}{|l|}{ Cost and weight } \\
\hline $\begin{array}{l}\text { Cost per loaf (ingredient costs } \\
\text { only) }\end{array}$ & $\$ N Z 1.50, \$ 3.00$ & $\begin{array}{l}\text { Set target values for baseline analyses (with the highest value still substantially } \\
\text { less than commercial artisan bread loafs in the current NZ setting in the \$NZ8 } \\
\text { plus range). }\end{array}$ \\
\hline Total weight of dry ingredients & $700-800 \mathrm{~g}$ & $\begin{array}{l}\text { Makes around one } \mathrm{kg} \text { of HHB loaf (given the addition of water to the recipe: } \\
\text { see below). }\end{array}$ \\
\hline \multicolumn{3}{|l|}{ Required ingredients } \\
\hline Active yeast mixture & 3 to 4 tsp (12-16 g) & $\begin{array}{l}\text { Basic requirement for bread design to ensure the bread rises, with } 12 \mathrm{~g} \text { for } \\
\text { the HHB\$1.5 loaf but slightly more }(16 \mathrm{~g}) \text { for the } H H B \$ 3 \text { loaf given the } \\
\text { increased weight of the seed ingredients. }\end{array}$ \\
\hline White or wholemeal flour & $\geq 550 \mathrm{~g}$ & $\begin{array}{l}\text { Set at } 50 \% \text { each for white and wholemeal flour for the HHB\$1.5 loaf; but at } \\
25 \% \text { white and } 75 \% \text { wholemeal for the HHB\$3 loaf (to avoid excessive } \\
\text { density and chewiness). }\end{array}$ \\
\hline Water & $\begin{array}{l}450 \mathrm{mls} \text { added to HHB\$1.5 } \\
\text { and } 500 \mathrm{mls} \text { to HHB\$3 }\end{array}$ & Evaporation of the water during baking is a determinant of the final loaf weight. \\
\hline Total weight of added seeds/nuts & $\leq 150 \mathrm{~g}$ & $\begin{array}{l}\text { This was an arbitrary upper limit to constrain bread density and chewiness } \\
\text { (especially relevant for older people and those with suboptimal dentition). } \\
\text { Nevertheless, it is a level still below that found in some commercial breads } \\
\text { e.g., one Finnish bread has } 17 \% \text { seeds by weight ("Fazer Alku Jyväpala"). } \\
\text { Ground linseed was used rather than whole linseed, given data on } \\
\text { bioavailability and gastrointestinal tolerance [56]. }\end{array}$ \\
\hline \multicolumn{3}{|l|}{ Key CVD-related nutrients } \\
\hline Sodium & $<350 \mathrm{mg} / 100 \mathrm{~g}$ & $\begin{array}{l}\text { Range for all the dry ingredients collectively (with a goal of }<300 \mathrm{mg} / 100 \mathrm{~g} \\
\text { for the cooked loafs). The salt substitute with potassium chloride (KCl) was } \\
\text { the preferred source of sodium (over normal salt) but was limited to a } \\
\text { maximum of } 1.5 \mathrm{tsp}(9 \mathrm{~g} \text { ) per loaf to avoid any bitterness. The range of } 250 \\
\text { to } 300 \mathrm{mg} / 100 \mathrm{~g} \text { in a final loaf would be substantially less than the mean } \\
\text { level in } 2013 \text { in NZ ( } 410 \mathrm{mg} / 100 \mathrm{~g} \text { ) [57] and for most breads in other high- } \\
\text { income countries e.g., the USA [58]. }\end{array}$ \\
\hline Alpha-linolenic acid (ALA) & Maximize & Maximized ahead of fiber and PUFA (first priority of the objective function). \\
\hline Dietary fiber & Maximize & Maximized ahead of PUFA (second priority of the objective function). \\
\hline $\begin{array}{l}\text { Polyunsaturated fatty acids } \\
\text { (PUFA) }\end{array}$ & Maximize & Maximized after maximizing fiber and ALA (third priority of the objective function). \\
\hline Potassium & Not specifically optimized & $\begin{array}{l}\text { Given the use of a } \mathrm{KCl} \text { containing salt-replacement, we focused on lowering } \\
\text { sodium rather than increasing potassium. }\end{array}$ \\
\hline
\end{tabular}




\section{Country comparisons of commercial breads}

For country comparisons we considered just OECD countries and we conducted internet searches for those which had online documentation of nutrient profiles on commercial breads. In particular we used the EuroFIR database [46] which had 15 freely accessible nutrient databases. Ultimately, the only OECD countries with such databases were: Canada, Czech Republic, Denmark, Finland, Greece, Iceland, Italy, the Netherlands, New Zealand, Slovakia, Sweden, Switzerland, United States and the United Kingdom. For these countries the nutrient data on the most standard pre-packaged white bread was obtained. Only six of these countries had nutrient data on any breads containing seeds or nuts (Denmark, Finland, Iceland, Netherlands, New Zealand and Switzerland). Where there were multiple such breads, the one with the highest level of PUFA was selected as a proxy for the highest level of seeds/nuts.

Bread price information was sourced from online supermarkets in each country. At first, an attempt to identifying the largest supermarket chain in each country was made. Failing this, a search of the online supermarkets in the capital city was performed. Out of the breads marketed in these online supermarkets, the lowest priced most standard white pre-packaged loaf was selected for price information. For breads with seeds/nuts, the price data was from the one with the highest seed/ nut level (based on the ingredient listing). For all the prices we calculated cost per $100 \mathrm{~g}$ and cost per $1000 \mathrm{~kJ}$ in US dollars using OECD exchange rates and purchasing power parity adjustments [47]. For specific nutrient and price methods details for each country see Additional file 1.

\section{Estimating mass production costs of $\mathrm{HHBs}$}

To estimate the cost of mass production of HHB loafs, publicly-available data for the cost-structure data of bread manufacture from the Canadian baking industry was used. Such data are not readily available in other countries (including New Zealand), presumably due to reasons of commercial sensitivity. This Canadian coststructure covered: "materials and supplies", "energy, water and vehicle fuel" and "production worker wages" [48]. We applied this to the cost of the cheapest supermarket white bread from New Zealand (NZ\$1.00 or US $\$ 0.68$ for a $600 \mathrm{~g}$ loaf) and assumed at this price it was basically "cost price" i.e., with no profit. Using recipes for a white loaf of bread [49], we then estimated how much more cheaply the ingredients for this commercial bread might typically cost the baking industry, compared to ingredient prices in the supermarket. This scalar was then applied to all the HHB ingredients and varying levels of profit margin were also considered (for the manufacturer and retailer). We assumed HHBs would be mass produced by existing bread manufacturers with existing plant and machinery and distribution networks. Further details on the methods are shown with the tabulated results.

\section{Results}

\section{Optimized HHB ingredient selection}

The optimized HHB $\$ 1.5$ loaf was characterized by having some wholemeal flour but the cost constraint resulted in only trivial levels of added seeds (Table 2, Fig. 1). The optimized HHB\$3 loaf (Fig. 1) had up to the maximum weight of seeds permitted (150 g dry ingredients per loaf, $12.6 \%$ of the final loaf weight). But linseed

Table 2 Dry ingredients of the two optimized "heart healthy breads" per $100 \mathrm{~g}$ of dry ingredient weight

\begin{tabular}{|c|c|c|c|c|}
\hline & \multicolumn{2}{|l|}{$\mathrm{HHB} \$ 1.5$} & \multicolumn{2}{|l|}{$\mathrm{HHB} \$ 3$} \\
\hline & Quantity of dry ingredients (g) & Percentage of dry ingredients & Quantity of dry ingredients (g) & Percentage of dry ingredients \\
\hline Wholemeal flour & 334 & $48 \%$ & 464 & $58 \%$ \\
\hline White flour & 334 & $48 \%$ & 155 & $19 \%$ \\
\hline Yeast & 12 & $2 \%$ & 16 & $2 \%$ \\
\hline Normal salt & 8 & $1 \%$ & 7 & $1 \%$ \\
\hline Salt substitute & 8 & $1 \%$ & 9 & $1 \%$ \\
\hline \multicolumn{5}{|l|}{ Nuts and seeds } \\
\hline Linseeds & 4 & $1 \%$ & 132 & $16 \%$ \\
\hline Walnuts & 0 & $0 \%$ & 18 & $2 \%$ \\
\hline Sunflower seeds & 0 & $0 \%$ & 1 & $0 \%$ \\
\hline Pumpkin seeds & 0 & $0 \%$ & 0 & $0 \%$ \\
\hline Sesame seeds & 0 & $0 \%$ & 0 & $0 \%$ \\
\hline \multicolumn{5}{|l|}{ Totals } \\
\hline All dry ingredients & 700 & $100 \%$ & 800 & $100 \%$ \\
\hline All nuts and seeds & 4 & $1 \%$ & 150 & $19 \%$ \\
\hline
\end{tabular}




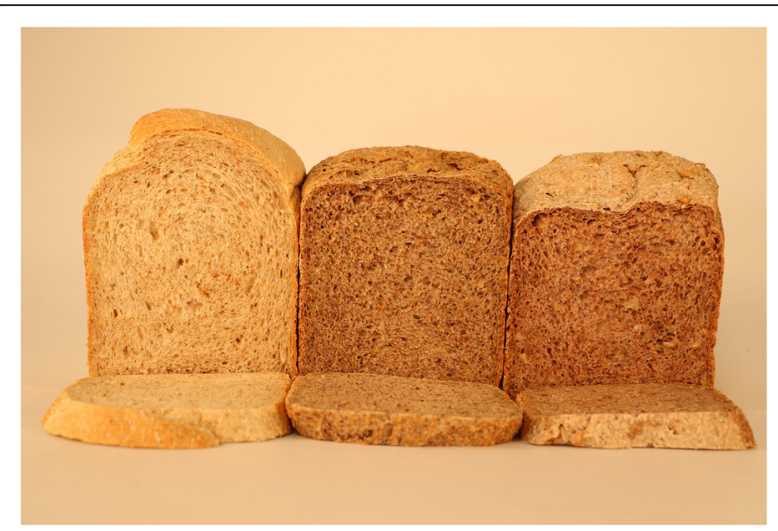

Fig. 1 The loaf on the left is the optimized HHB\$1.5 loaf. The loaf in the middle is the optimized $\mathrm{HHB} \$ 3$ loaf which is high in ground linseed. The loaf on the right is one that is high in walnut (but which was subsequently excluded from further study due to its relatively high cost at NZ\$5). (Photography: Pascale Otis)

dominated over walnut and other seeds due to it being a low-cost source of ALA.

\section{Heart health and other nutrients in the loafs}

In indicative rankings, the HHB $\$ 1.5$ loaf appeared to be superior to the commercial white loafs from the 15 high-income countries in three out of the eight heart health nutrient categories (Table 3, Fig. 2). That is, lower in sodium, and higher in potassium and the ratio of potassium to sodium. It ranked relatively highly in terms of lower saturated fatty acids (SFA) and a high PUFA/SFA ratio.

The HHB\$3 loaf appeared to be nutritionally superior to the commercial loafs with seeds/nuts from six countries in six out of the eight heart health categories (Table 3, Fig. 2). While it had the best PUFA/SFA ratio, it did not have the highest levels of PUFA and lowest levels of SFA. It also appeared superior to the HHB $\$ 1.5$ loaf in all eight heart health categories except for low saturated fat. Some of the differences were relatively large, such as the ALA level in the HHB\$3 loaf being 26 times the median for the white loafs and 2.2 times the median for the commercial high seed/nut loafs.

In terms of other nutrients, the HHB $\$ 1.5$ bread appeared to perform better than most commercial white breads (e.g., highest in iodide and zinc) (Table 3). But it was competing with some breads which were fortified with calcium, folate and iron. However, relative to the commercial seed breads, the HHB\$3 loaf was in the top two rankings for: calcium, folate, iodide, iron, low sugars, and low energy density.

In terms of value-per-weight, a commercial white loaf from the UK was slightly cheaper than the HHB $\$ 1.50$ loaf (at US\$0.07 vs US\$0.10 per $100 \mathrm{~g}$ loaf, Table 3). The HHB $\$ 1.5$ loaf also performed relatively well in terms of price per kJ of food energy (fourth equal). But compared to the other seed/nut loafs, the HHB $\$ 3$ loaf was by far the best value-per-weight at US\$0.17 vs a mean of US\$0.85 per $100 \mathrm{~g}$.

\section{Possible mass production costs of HHB loafs}

From the documented cost-structure of the Canadian baking industry, we estimated that the New Zealand baking industry might be obtaining bread ingredients at around $72 \%$ of supermarket prices that we used in costing the HHB loafs in the preceding analyses. We used this percentage to estimate that mass production of HHB (at zero profit) would be likely to reduce the cost of the various loafs to: US\$0.99 for the HHB\$1.5 loaf, and to US\$1.75 for the HHB\$3 loaf (Table 4). Such costs might approximate production costs for a non-profit institution such as a hospital kitchen with its own bakery.

Where commercial manufacturers/retailers produced and sold HHB loafs (e.g., as per contracts for a government voucher system for provision of HHB) a profit margin would be relevant (Table 4). For example, a $25 \%$ profit margin shared by producers and retailers would push up the price to: US\$1.24 for the HHB $\$ 1.5$ loaf and US\$2.19 for the HHB\$3 loaf (Table 4). Based on these estimates and a $25 \%$ profit mark-up, the HHB $\$ 1.5$ loaf at US\$0.12 per $100 \mathrm{~g}$ would remain well under half that of the median for the commercial white loafs from the 15 high-income countries in Table 3. Likewise the HHB $\$ 3$ loaf at this mark-up would still be the lowest cost per $100 \mathrm{~g}$ out of the seed/nut loafs in Table 3 .

\section{Discussion}

\section{Main findings and interpretation}

This proof-of-concept work generated two potential HHB designs which were generally superior to commercial breads from 15 high-income (OECD) countries from a nutrient/CVD prevention perspective (i.e., in terms of sodium, potassium, fatty acid ratios and dietary fiber). The higher levels in the HHB\$3 bread were often substantial e.g., 26 times the median ALA level of the white loafs. Furthermore, in principle the higher fiber levels in the HHBs could contribute to non-CVD benefits such as colorectal cancer prevention [31]. Similarly, the walnut in the HHB $\$ 3$ loaf could potentially contribute in a small way to cancer prevention [38, 39], but obviously a diet designed to minimize cancer risk has many other aspects such as being high in fruit and vegetables.

Of relevance to food security, the HHB $\$ 1.5$ loaf was better value-per-weight than all but one of the commercial white loafs from the 15 countries. The HHB $\$ 3$ also outperformed all the seed/nut loafs at a fifth the cost per $100 \mathrm{~g}$ of the average. Furthermore, the relatively higher level of dietary fiber in the HHB loafs might mean they also provide better value in terms of inducing satiety. 
Table 3 Comparisons of the nutrient levels of the "heart healthy bread" loafs with commercial breads (nutrients and costs, all values per $100 \mathrm{~g}$ unless indicated otherwise)

\begin{tabular}{|c|c|c|c|c|c|c|c|c|}
\hline \multirow[t]{2}{*}{ Nutrient/cost component } & \multicolumn{2}{|c|}{$\begin{array}{l}\text { White breads } \\
\text { ( } n=15 \text { countries) }\end{array}$} & \multirow[t]{2}{*}{ HHB\$1.5 } & \multirow[t]{2}{*}{ Rank of HHB\$1.5 } & \multicolumn{2}{|c|}{$\begin{array}{l}\text { Breads with seeds/ } \\
\text { nuts ( } n=6 \text { countries) }\end{array}$} & \multirow[t]{2}{*}{$\mathrm{HHB} \$ 3$} & \multirow[t]{2}{*}{ Rank of $\mathrm{HHB} \$ 3^{\mathrm{a}}$} \\
\hline & Median & IQR & & & Median & IQR & & \\
\hline \multicolumn{9}{|l|}{ Eight heart health relevant characteristics } \\
\hline Alpha-linolenic acid (ALA) & 0.10 & $0.05-0.17$ & 0.08 & $6 / 8$ & 1.19 & $0.64-1.44$ & 2.62 & $1 / 3$ \\
\hline Total polyunsaturated fatty acids (PUFA) (g) & 0.66 & $0.51-1.33$ & 0.52 & $10=/ 14$ & 4.52 & $2.98-5.73$ & 4.19 & $4 / 6$ \\
\hline Total saturated fatty acids (SFA) (g) & 0.40 & $0.29-0.70$ & 0.14 & $2 / 13$ & 1.25 & $0.89-1.83$ & 0.62 & $5 / 6$ \\
\hline Ratio PUFA/SFA & 2.1 & $1.7-2.5$ & 3.7 & $3 / 13$ & 4.4 & $3.0-4.7$ & 6.8 & $1 / 6$ \\
\hline Sodium (mg) & 498 & $457-528$ & 309 & $1 / 15$ & 464 & $437-472$ & 231 & $1 / 6$ \\
\hline Potassium (mg) & 130 & $115-157$ & 561 & $1 / 15$ & 220 & $195-277$ & 647 & $1 / 6$ \\
\hline Ratio of potassium to sodium & 0.3 & $0.2-0.3$ & 1.8 & $1 / 15$ & 0.5 & $0.4-0.6$ & 2.8 & $1 / 6$ \\
\hline Dietary fiber (g) & 3.1 & $2.6-4.3$ & 4.8 & $4 / 15$ & 5.2 & $4.3-5.4$ & 8.1 & $1 / 6$ \\
\hline \multicolumn{9}{|l|}{ Other micronutrients } \\
\hline Calcium (mg) & 97 & $54-110$ & 23 & $14 / 15$ & 40 & $37-43$ & 51 & $2 / 6$ \\
\hline $\begin{array}{l}\text { Folate (mcg) (including synthetic forms } \\
\text { in some fortified white breads) }\end{array}$ & 30 & $27-41$ & 65 & $3 / 12$ & 52 & $44-57$ & 83 & $2 / 6$ \\
\hline lodide (mcg) & 3.8 & $1.2-6.0$ & 40.0 & $1 / 8$ & 5.3 & $3.1-16.2$ & 29.6 & $2 / 6$ \\
\hline Iron (mg) & 1.6 & $1.1-2.5$ & 2.2 & $5 / 14$ & 1.7 & $1.4-2.7$ & 2.8 & $2 / 6$ \\
\hline Selenium (mcg) & 5.8 & $2.6-14.3$ & 3.0 & $8 / 10$ & 5.2 & $4.1-8.0$ & 6.4 & $3 / 6$ \\
\hline Zinc (mg) & 0.8 & $0.7-1.0$ & 1.4 & $1=/ 13$ & 1.4 & $1.1-1.9$ & 1.9 & $3 / 6$ \\
\hline \multicolumn{9}{|l|}{ Selected other macronutrients } \\
\hline Dietary energy (kJ) & 1047 & $1026-1169$ & 951 & $2 / 14$ (if low is best) & 1188 & $1168-1291$ & 1036 & $2 / 5$ (if low is best) \\
\hline Protein (g) & 8.4 & $8.3-9.1$ & 7.4 & $14 / 15$ & 10.6 & $9.5-11.6$ & 8.8 & $6 / 6$ \\
\hline Sugars (total) (g) & 3.5 & $1.7-4.8$ & 0.5 & $2 / 10$ & 2.2 & $1.45-3.4$ & 0.6 & $2 / 5$ \\
\hline \multicolumn{9}{|l|}{ Cost (relevant to food security) ${ }^{c}$} \\
\hline Cost per $100 \mathrm{~g}$ of loaf (US\$) & 0.28 & $0.21-0.34$ & 0.10 & $2 / 15$ & 0.73 & $0.64-0.95$ & 0.17 & $1 / 5$ \\
\hline Cost per $1000 \mathrm{~kJ}$ of food energy (US\$) & 0.17 & $0.12-0.20$ & 0.11 & $4=/ 14$ & 0.34 & $0.33-0.38$ & 0.20 & $2 / 5$ \\
\hline
\end{tabular}

${ }^{a}$ Indicative rank in terms of the best values from a health perspective and food security perspective (some of these ranks could change with a larger sample of comparison breads). From an energy security perspective, low cost per kJ is best. But in terms of weight control, low kJ per $100 \mathrm{~g}$ (low energy density) is probably best. Of note is that the nutrient data in some of the national databases had some gaps e.g., for ALA and iodide (both only 8 of the 15 databases for white bread) ${ }^{b}$ Some of these nutrient characteristics overlap to some extent (e.g., the two ratios reflect the amounts of the two relevant components) ${ }^{\mathrm{C}} \mathrm{HHB}$ costing based on supermarket prices for ingredients and no other production costs. See Table 4 for more details on possible mass production costs For specific nutrient and price methods details for each country see Supplementary Information $I Q R$ interquartile range

Such a satiety benefit has been reported in a study on wholegrain vs refined bread [50], but not in one of nutenriched bread vs nut-free bread [51].

The mass production cost estimates (Table 4) suggest it would be feasible to produce the HHB\$3 loaf in a place like a hospital kitchen at around US $\$ 1.75$ per loaf. The voucher costs for government for this type of loaf might be US $\$ 2.19$ per loaf when assuming a $25 \%$ markup by the contracted manufacturer and retailers (or US\$2.63 if a $50 \%$ mark-up is assumed). At two loafs a week per person (e.g., for a patient at high risk of CVD) this would be US\$274 per year in voucher costs for a $100 \%$ subsidized loaf supply (albeit not including the voucher delivery and other administration costs).
Whether this is justified from a funder perspective would depend on many issues such as the priority given to protecting public health and the health economics (e.g., the cost-effectiveness of such a program should ideally be modeled before any implementation).

\section{Study strengths and limitations}

This study was, to our knowledge, the first to study the issue of the optimized design of bread from a heart health and a low-cost perspective using linear programing. We consider that the constraints imposed, and the typical ingredients used, will help ensure that such designs have at least some acceptability in high-income countries where there is often a majority of adults who 


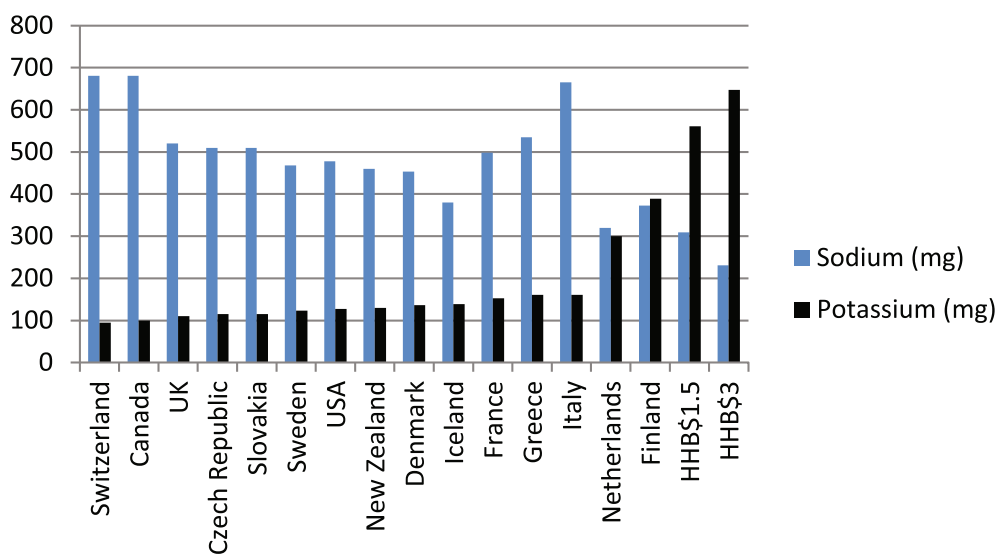

Fig. 2 Levels of potassium and sodium in white bread loafs from 15 countries compared to the two "optimized" heart healthy bread (HHB) designs

currently consume at least a light-grained bread (e.g., as per New Zealand [52]). Indeed, some countries currently have seed/nut breads sold commercially at up to $17 \%$ seeds by weight (for Finland, see Table 1).

Nevertheless, this was still just a proof-of-concept study which only considered two potential designs of HHB. Indeed, the full "design-universe" of such potential breads is large and might include other relatively healthy additional ingredients such as: soy, sourdough, dried fruit, high phenolic olive oil, and extra fiber sources (e.g., wheat bran and rye flour), (see the Methods). A version particularly suitable for women of child-bearing age could also include added folic acid for preventing neural tube defects.

A further limitation was the relatively simplistic nature of our cost estimates for mass production of the two HHB designs. Nevertheless, it is plausible that the coststructure of Canadian bread manufacture is not markedly different from other high-income countries. Our costing estimates also didn't consider administrative costs associated with setting up and running any HHB voucher system (e.g., for people with CVD risk factors). It also did not consider the environmental impact, as per Swedish work on emissions of oxides of carbon, sulfur and nitrogen from bread production [53]. Finally, we did not explore various other complexities with bringing any HHB to market. For example, consumer taste testing would be required (see below), and packaging would need to be designed. For example, packaging would probably need to display potassium levels to help people with renal disease or on particular medication such as diuretics to avoid excessive intake.

\section{Implications for further research and policy}

Consumer testing prior to mass production of any $\mathrm{HHB}$ could be done by a commercial bread manufacturer as

Table 4 Estimated mass production costs for "heart healthy bread" designs ${ }^{a}$

\begin{tabular}{|c|c|c|c|c|c|c|}
\hline \multirow[t]{2}{*}{ Components } & \multicolumn{2}{|c|}{ Commercial white loaf in NZ } & \multicolumn{2}{|l|}{ HHB\$1.5 loaf } & \multicolumn{2}{|l|}{$\mathrm{HHB} \$ 3$ loaf } \\
\hline & $\overline{N Z \$}$ & $\%$ & $\overline{N Z \$(U S \$)}$ & $\%$ & $\overline{N Z \$(U S \$)}$ & $\%$ \\
\hline Food ingredients & 0.70 & 70 & 1.15 & 79 & 2.27 & 88 \\
\hline Packaging & 0.01 & 1 & 0.01 & 1 & 0.01 & 1 \\
\hline Production wages & 0.24 & 24 & 0.24 & 16 & 0.24 & 9 \\
\hline Vehicle fuel costs, energy and water & 0.05 & 5 & 0.05 & 3 & 0.05 & 2 \\
\hline Total & 1.00 & 100 & $1.46(0.99)$ & 100 & $2.57(1.75)$ & 100 \\
\hline Total price after profit mark-up of $10 \%$ & & & $1.60(1.09)$ & & $2.83(1.93)$ & \\
\hline - of $25 \%$ mark-up & & & $1.82(1.24)$ & & $3.21(2.19)$ & \\
\hline - of $50 \%$ mark-up & & & $2.19(1.49)$ & & $3.86(2.63)$ & \\
\hline Loaf weight (g) - average & 600 & & 1036 & & 1190 & \\
\hline - range & & & 1004 to 1057 & & 1184 to 1195 & \\
\hline Price NZ\$/100 g at $25 \%$ mark-up (US\$) & & & $0.18(0.12)$ & & $0.27(0.18)$ & \\
\hline
\end{tabular}

a Relatively simple cost-structure based on the Canadian baking industry [48] and this was used to estimate the ability of the NZ baking industry to obtain cheaper ingredients relative to the supermarket prices used in the earlier HHB analyses (see Methods). All the prices shown are inclusive of a NZ sales tax (GST) of $15 \%$. For this analysis we assumed HHBs would be mass produced by existing bread manufacturers with existing plant and machinery and distribution networks 
part of their routine product development processes. Similarly, an institution such as a public hospital could "market test" the acceptability of various HHBs on staff in a hospital cafeteria. The latter could be done in conjunction with health orientated non-governmental organizations which exist in many countries and sometimes have "endorsement label programs" for heart healthy foods (e.g., as in New Zealand [54]). If there were concerns about public acceptability of bread design, then a more incremental approach could involve slowly phasing down the levels of white flour and sodium while phasing up the levels of linseed and salt substitute in the HHBs promoted for mass consumption. Final bread products could also be considered in terms of the health claims that could be justifiably made on HHB packaging or in marketing about these being "functional foods". Many countries have rules around such claims with one example being the European Food Safety Authority's process for European Union countries [55].

Epidemiological and economic modeling should also attempt to quantify the effectiveness (in qualityadjusted life-years gained) and cost-effectiveness of a government-run voucher system for a HHB version for those at increased CVD risk (and even for those at increased risk of cancer given the extra fiber and seeds in the HHB $\$ 3$ loaf).

\section{Conclusions}

This proof-of-concept study suggests it is possible to design breads that are nutritionally far superior from a heart health perspective to commercially available breads as well as being lower cost. Such HHB designs could be utilized in conjunction with a governmentfunded voucher system for those at high risk of CVD. This could be one (albeit small) part of comprehensive CVD prevention programs which ideally should cover multiple nutritional and physical activity interventions.

\section{Ethical review}

This was not relevant for this modeling study which did not involve human subjects.

\section{Consent to publish}

Not applicable.

Availability of data and materials

All supporting data is in Additional file 1.

\section{Additional file}

Additional file 1: Additional Methods and Results for the Study on Health Healthy Bread. (DOCX $65 \mathrm{~kb})$

\section{Abbreviations}

ALA: alpha-linolenic acid; CVD: cardiovascular disease; HHB: heart healthy bread; IQR: interquartile range; NCDs: non-communicable diseases; NZ: New Zealand; OECD: Organisation for Economic Co-operation and Development; PUFA: polyunsaturated fatty acid; SFA: saturated fatty acid.

\section{Competing interests}

The authors declare that they have no competing interests.

\section{Authors' contributions}

Designing the study: NW, NNg, CC, and TB. Collecting the data: NW, SR. Data analyses: NNg, NW. Drafting the initial manuscript: NW. Manuscript revision: all authors. All authors read and approved the final manuscript.

\section{Acknowledgements}

We thank our work colleagues for their helpful comments on bread design issues, Pascale Otis for the photography, and the journal's reviewers for constructive critique.

\section{Funding}

The Burden of Disease Epidemiology, Equity and Cost-Effectiveness Programme is funded by the Health Research Council of New Zealand (10/248).

Received: 26 November 2015 Accepted: 9 April 2016

Published online: 18 April 2016

\section{References}

1. Lozano R, Naghavi M, Foreman K, Lim S, Shibuya K, Aboyans V, Abraham J, Adair T, Aggarwal R, Ahn SY et al. Global and regional mortality from 235 causes of death for 20 age groups in 1990 and 2010: a systematic analysis for the Global Burden of Disease Study 2010. Lancet. 2012;380(9859):2095-128.

2. Global Burden of Disease Study Collaborators. Global, regional, and national incidence, prevalence, and years lived with disability for 301 acute and chronic diseases and injuries in 188 countries, 1990-2013: a systematic analysis for the Global Burden of Disease Study 2013. Lancet. 2015;386(9995):743-800.

3. Lim SS, Vos T, Flaxman AD, Danaei G, Shibuya K, Adair-Rohani H, Amann $M$, Anderson HR, Andrews KG, Aryee $M$ et al. A comparative risk assessment of burden of disease and injury attributable to 67 risk factors and risk factor clusters in 21 regions, 1990-2010: a systematic analysis for the Global Burden of Disease Study 2010. Lancet. 2012;380(9859):2224-60

4. Block G. Foods contributing to energy intake in the US: data from NHANES III and NHANES 1999-2000. J Food Compos Anal. 2004;17(3-4):439-47.

5. Johnson-Down L, Ritter H, Starkey $\sqcup$, Gray-Donald K. Primany food sources of nutrients in the diet of Canadian adults. Can J Diet Pract Res. 2006;67(1):7-13.

6. Whitton C, Nicholson SK, Roberts C, Prynne CJ, Pot GK, Olson A, Fitt E, Cole D, Teucher B, Bates B et al. National Diet and Nutrition Survey: UK food consumption and nutrient intakes from the first year of the rolling programme and comparisons with previous surveys. $\mathrm{Br} J$ Nutr. 2011;106(12):1899-914.

7. European Commission: Survey on members states implementation of the EU salt reduction framework: Directorate-General Health and Consumers, 2012. Available from: http://ec.europa.eu/health/nutrition_physical_activity/ docs/salt_report1_en.pdf. (Accessed 16 April 2016).

8. Quilez J, Salas-Salvado J. Salt in bread in Europe: potential benefits of reduction. Nutr Rev. 2012;70(11):666-78.

9. Rubinstein A, Garcia Marti S, Souto A, Ferrante D, Augustovski F. Generalized cost-effectiveness analysis of a package of interventions to reduce cardiovascular disease in Buenos Aires, Argentina. Cost Eff Resour Alloc. 2009; 7:10

10. Rubinstein A, Colantonio L, Bardach A, Caporale J, Marti SG, Kopitowski K, Alcaraz A, Gibbons L, Augustovski F, Pichon-Riviere A. Estimation of the burden of cardiovascular disease attributable to modifiable risk factors and cost-effectiveness analysis of preventative interventions to reduce this burden in Argentina. BMC Public Health. 2010;10:627.

11. Ferrante D, Konfino J, Mejia R, Coxson P, Moran A, Goldman L, Perez-Stable EJ. The cost-utility ratio of reducing salt intake and its impact on the incidence of cardiovascular disease in Argentina [In Spanish]. Rev Panam Salud Publica. 2012;32(4):274-80. 
12. Cobiac $L$, Vos $T$, Veerman $J$. Cost-effectiveness of interventions to reduce dietary salt intake. Heart. 2010;96(23):1920-5.

13. Cobiac L, Magnus A, Lim S, Barendregt JJ, Carter R, Vos T. Which interventions offer best value for money in primary prevention of cardiovascular disease? PLoS ONE. 2012;7(7), e41842.

14. Nghiem N, Blakely T, Cobiac $L$, Pearson AL, Wilson N. Health and economic impacts of eight different dietary salt reduction interventions. PLOS ONE. 2015;10(4), e0123915.

15. Bertram MY, Steyn K, Wentzel-Viljoen E, Tollman S, Hofman KJ. Reducing the sodium content of high-salt foods: effect on cardiovascular disease in South Africa. S Afr Med J. 2012;102(9):743-5.

16. Quilez J, Salas-Salvado J. The feasibility and acceptability of reducing salt in partially baked bread: a Spanish case study. Public Health Nutr. 2015 (E-publication 6 May):1-5.

17. Li N, Prescott J, Wu Y, Barzi F, Yu X, Zhao L, Neal B, China Salt Substitute Study Collaborative $\mathrm{G}$. The effects of a reduced-sodium, high-potassium salt substitute on food taste and acceptability in rural northern China. Br J Nutr. 2009;101(7):1088-93.

18. Braschi A, Gill L, Naismith DJ. Partial substitution of sodium with potassium in white bread: feasibility and bioavailability. Int J Food Sci Nutr. 2009;60(6):507-21.

19. Threapleton DE, Greenwood DC, Evans CE, Cleghorn CL, Nykjaer C, Woodhead C, Cade JE, Gale CP, Burley VJ. Dietary fibre intake and risk of cardiovascular disease: systematic review and meta-analysis. BMJ. 2013;347:f6879.

20. Threapleton DE, Greenwood DC, Evans CE, Cleghorn CL, Nykjaer C, Woodhead C, Cade JE, Gale CP, Burley VJ. Dietary fiber intake and risk of first stroke: a systematic review and meta-analysis. Stroke. 2013;44(5):1360-8.

21. Khalesi S, Irwin C, Schubert M. Flaxseed consumption may reduce blood pressure: a systematic review and meta-analysis of controlled trials. J Nutr. 2015;145:758-65.

22. Ursoniu S, Sahebkar A, Andrica F, Serban C, Banach M, Lipid Blood Pressure Meta-analysis Collaboration Group. Effects of flaxseed supplements on blood pressure: A systematic review and meta-analysis of controlled clinical trial. Clin Nutr. 2015 (E-publication 29 May).

23. Briend A, Darmon N, Ferguson E, Erhardt JG. Linear programming: a mathematical tool for analyzing and optimizing children's diets during the complementary feeding period. J Pediatr Gastroenterol Nutr. 2003;36(1):12-22.

24. McMahon E, Webster J, O'Dea K, Brimblecombe J. Dietary sodium and iodine in remote Indigenous Australian communities: will salt-reduction strategies increase risk of iodine deficiency? A cross-sectional analysis and simulation study. BMC Public Health. 2015;15:1318.

25. Rambeloson ZJ, Darmon N, Ferguson EL. Linear programming can help identify practical solutions to improve the nutritional quality of food aid Public Health Nutr. 2008;11(4):395-404.

26. Conforti P, D'Amicis A. What is the cost of a healthy diet in terms of achieving RDAs? Public Health Nutr. 2000;3(3):367-73.

27. Peng YG, Li W, Wen XX, Li Y, Hu JH, Zhao LC. Effects of salt substitutes on blood pressure: a meta-analysis of randomized controlled trials. Am J Clin Nutr. 2014;100(6):1448-54.

28. Bolhuis DP, Temme EH, Koeman FT, Noort MW, Kremer S, Janssen AM. A salt reduction of $50 \%$ in bread does not decrease bread consumption or increase sodium intake by the choice of sandwich fillings. J Nutr. 2011;141(12):2249-55.

29. Hollaender $\mathrm{PL}$, Ross $\mathrm{AB}$, Kristensen M. Whole-grain and blood lipid changes in apparently healthy adults: a systematic review and meta-analysis of randomized controlled studies. Am J Clin Nutr. 2015;102:556-2.

30. Wu H, Flint AJ, Qi Q, van Dam RM, Sampson LA, Rimm EB, Holmes MD, Willett WC, Hu FB, Sun Q. Association between dietary whole grain intake and risk of mortality: Two large prospective studies in US men and women. JAMA Int Med. 2015;175(3):373-84.

31. Aune D, Chan DS, Lau R, Vieira R, Greenwood DC, Kampman E, Norat T. Dietary fibre, whole grains, and risk of colorectal cancer: systematic review and dose-response meta-analysis of prospective studies. BMJ. 2011;343:d6617.

32. Rodriguez-Leyva D, Weighell W, Edel AL, LaVallee R, Dibrov E, Pinneker R, Maddaford TG, Ramjiawan B, Aliani M, Guzman R et al. Potent antihypertensive action of dietary flaxseed in hypertensive patients. Hypertens. 2013;62(6):1081-9.

33. Caligiuri SP, Edel AL, Aliani M, Pierce GN. Flaxseed for hypertension: implications for blood pressure regulation. Curr Hypertens Rep. 2014;16(12):499
34. Prasad K. Flaxseed and cardiovascular health. J Cardiovasc Pharmacol. 2009;54(5):369-77.

35. Edel AL, Rodriguez-Leyva D, Maddaford TG, Caligiuri SP, Austria JA, Weighell W, Guzman R, Aliani M, Pierce GN. Dietary flaxseed independently lowers circulating cholesterol and lowers it beyond the effects of cholesterol lowering medications alone in patients with peripheral artery disease. J Nutr. 2015;145:749-57.

36. Banel DK, Hu FB. Effects of walnut consumption on blood lipids and other cardiovascular risk factors: a meta-analysis and systematic review. Am J Clin Nutr. 2009;90(1):56-63.

37. Kris-Etherton PM. Walnuts decrease risk of cardiovascular disease: a summary of efficacy and biologic mechanisms. J Nutr. 2014;144(4 Suppl):547S-54.

38. Grosso G, Yang J, Marventano S, Micek A, Galvano F, Kales SN. Nut consumption on all-cause, cardiovascular, and cancer mortality risk: a systematic review and meta-analysis of epidemiologic studies. Am J Clin Nutr. 2015;101(4):783-93.

39. van den Brandt PA, Schouten LJ. Relationship of tree nut, peanut and peanut butter intake with total and cause-specific mortality: a cohort study and meta-analysis. Int J Epidemiol. 2015;44:1038-49.

40. Anderson JW, Bush HM. Soy protein effects on serum lipoproteins: a quality assessment and meta-analysis of randomized, controlled studies. J Am Coll Nutr. 2011;30(2):79-91.

41. Penas E, Diana M, Frias J, Quilez J, Martinez-Villaluenga C. A multistrategic approach in the development of sourdough bread targeted towards blood pressure reduction. Plant Foods Hum Nutr. 2015;70(1):97-103.

42. Hohmann CD, Cramer H, Michalsen A, Kessler C, Steckhan N, Choi K, Dobos $G$. Effects of high phenolic olive oil on cardiovascular risk factors: a systematic review and meta-analysis. Phytomedicine. 2015;22(6):631-40.

43. Gerdessen JC, de Vries JH. Diet models with linear goal programming: impact of achievement functions. Eur J Clin Nutr. 2015;69(11):1272-8.

44. Ministry of Health (New Zealand) and the New Zealand Institute for Plant and Food Research Limited: The Concise New Zealand Food Composition Tables 10th Edition 2013: Ministry of Health (New Zealand) and the New Zealand Institute for Plant and Food Research Limited; 2014.

45. Kris-Etherton PM, Taylor DS, Yu-Poth S, Huth P, Moriarty K, Fishell V, Hargrove RL, Zhao G, Etherton TD. Polyunsaturated fatty acids in the food chain in the United States. Am J Clin Nutr. 2000;71(1 Suppl):179S-88.

46. EuroFIR European Food Information Resource: Food composition databases. URL: http://www.eurofir.org/?page_id=96. (Accessed 16 April 2016).

47. OECD: OECD.Stats, Table 4. PPPs and exchange rates. URL: https://stats.oecd. org/Index.aspx?DataSetCode=SNA_TABLE4\# . (Accessed 16 April 2016).

48. Industry Canada: Bread and Bakery Product Manufacturing (NAICS 31181): Manufacturing costs. https://www.ic.gc.ca/app/scr/sbms/sbb/cis/ manufacturingCosts.html?code=31181\&lang=eng . (Accessed 16 April 2016).

49. Panasonic Corporation. Automatic Bread Maker: Operating Instructions and Recipes (Household use). Model No. SD-2501. Macquarie Park: Panasonic Corporation; 2011.

50. Kristensen M, Jensen M, Riboldi G, Petronio M, Bügel S, Toubro S, Tetens I, Astrup A. Wholegrain vs. refined wheat bread and pasta. Effect on postprandial glycemia, appetite, and subsequent ad libitum energy intake in young healthy adults. Appetite. 2010;54(1):163-9.

51. Devi A, Chisholm A, Gray A, Tey S, Williamson-Poutama D, Cameron S, Brown R. Nut-enriched bread is an effective and acceptable vehicle to improve regular nut consumption. Eur J Nutr. 2015 (E-publication 10 September).

52. University of Otago and Ministry of Health. A Focus on Nutrition: Key Findings of the 2008/09 New Zealand Adult Nutrition Survey. Wellington: Ministry of Health; 2011. http://www.health.govt.nz/publication/focus-nutrition-keyfindings-2008-09-nz-adult-nutrition-survey. (Accessed 16 April 2016).

53. Sundkvist A, Jansson A, Larsson P. Strengths and limitations of localizing food production as a sustainability-building strategy — an analysis of bread production on the island of Gotland, Sweden. Ecol Econ. 2001;37:217-27.

54. Wilson N, Nghiem N, Eyles H, Ni Mhurchu C, Cobiac LJ, Pearson AL, Cleghorn C, Blakely T. Possible impact of the tick programme in New Zealand on selected nutrient intakes: tentative estimates and methodological complexities. N Z Med J. 2014;127(1399):85-8.

55. European Food Safety Authority: "New function" health claims under Article 13.5. (updated January 2015). http://www.efsa.europa.eu/en/topics/topic/ article13-5. (Accessed 16 April 2016).

56. Austria JA, Richard MN, Chahine MN, Edel AL, Malcolmson LJ, Dupasquier CM, Pierce GN. Bioavailability of alpha-linolenic acid in subjects after 
ingestion of three different forms of flaxseed. J Am Coll Nutr. 2008;27(2):214-21.

57. Monro D, Mhurchu CN, Jiang Y, Gorton D, Eyles H. Changes in the sodium content of New Zealand processed foods: 2003-2013. Nutrients. 2015;7(6):4054-67.

58. United States Department of Agriculture Agricultural Research Service:

National Nutrient Database for Standard Reference Release 27.

http://ndb.nal.usda.gov/ndb/search. (Accessed 16 April 2016).

Submit your next manuscript to BioMed Central and we will help you at every step:

- We accept pre-submission inquiries

- Our selector tool helps you to find the most relevant journal

- We provide round the clock customer support

- Convenient online submission

- Thorough peer review

- Inclusion in PubMed and all major indexing services

- Maximum visibility for your research

Submit your manuscript at www.biomedcentral.com/submit
Biomed Central 